\title{
RBEP
}

\section{Perfil, concepções e práticas pedagógicas de professores que atuam em turmas multisseriadas de escolas públicas de Sergipe}

Cláudia da Mota Darós Parente

http://dx.doi.org/10.1590/S2176-6681/304612686

\section{Resumo}

Analisa alguns aspectos da organização da escolarização em multisséries, tomando-se como referência o Estado de Sergipe e descrevendo o perfil, as concepções e as práticas pedagógicas de professores que atuam em turmas multisseriadas de escolas públicas. Os dados apresentados são decorrentes da análise estatística de informações disponibilizadas pelo Instituto Nacional de Estudos e Pesquisas Educacionais Anísio Teixeira (Inep) e de pesquisas realizadas com professores de escolas públicas de Sergipe. A pesquisa mostrou que a organização da escolarização em multisséries possui diferentes formas e tem como pressuposto central a junção de anos/séries, desconsiderando o elemento idade e inibindo uma possível intervenção pedagógica decorrente da diversidade de sujeitos e tempos de vida. Por isso, é preciso que os professores tenham um olhar mais atento aos sujeitos do campo e construam uma intervenção pedagógica que ultrapasse os aspectos administrativos de enturmação. A análise das concepções e das práticas de professores que atuam em 
turmas multisseriadas evidenciou que o trabalho docente está engessado por determinações externas e por barreiras administrativas, inibindo novas reflexões e práticas que rompam com as lógicas tradicionais da seriação, permeadas de elementos excludentes. O artigo pretende contribuir para a disseminação de reflexões e políticas na área da educação do campo, sobretudo em escolas que possuem organização da escolarização em multisséries.

Palavras-chave: multisseriação; educação do campo; prática pedagógica.

\section{Abstract \\ Profile, conceptions and pedagogical practices of teachers working in multigrade classes of public schools in Sergipe}

This article examines some aspects of the organization of multigrade schooling, taking as reference the state of Sergipe. It describes the profile, the conceptions and pedagogical practices of teachers working in multigrade classes in public schools. The data presented result from a statistical analysis of information collected by Instituto Nacional de Estudos e Pesquisas Educacionais Anísio Teixiera (Inep) and from researches realized with public school teachers of Sergipe. The research has shown that the organization of multigrade schooling has different patterns and its central premise is the junction of years/grades, disregarding the age factor and inhibiting a possible pedagogical intervention, which considers the diversity of subjects and their lifetime. Therefore, it is necessary that teachers have a closer look at subjects of education in rural areas and build an educational intervention that goes beyond administrative aspects of formation of classes. The analysis of conceptions and practices of the teachers working in multigrade classes showed that the teaching work is obstructed by external determinations and by administrative barriers, inhibiting new reflections and practices that break up with the traditional logic of grades, permeated of excluding elements. The article aims to contribute to the dissemination of reflections and policies in the area of country education, especially for schools organized by multigrade schooling.

Keywords: multigrade teaching; country education; pedagogical practice.

\footnotetext{
Os tempos escolares podem ser didaticamente divididos em: tempos de escola, tempos de formação/escolarização e tempos na escola (Parente, 2006). Diante dessa divisão, a multisseriação pode ser entendida como uma das várias formas de organização da escolarização.
}

\section{Introdução}

A multisseriação é uma forma de organização da escolarização ${ }^{1}$ previamente determinada pelos sistemas de ensino e cujo formato interfere nas práticas pedagógicas dos professores. Portanto, o questionamento 
central do presente trabalho é: diante do formato multisseriado previamente determinado, como os professores - que possuem perfil e concepções específicas acerca da multisseriação - elaboram, organizam, planejam e desenvolvem suas práticas pedagógicas, reproduzindo ou rompendo no todo ou em parte com as lógicas pré-existentes?

O presente estudo oferece contribuição ao estado da arte da educação do campo, área que vem se ampliando nos últimos anos, principalmente em função do fortalecimento do movimento Por uma Educação do Campo, surgido na década de 1990 (Arroyo; Caldart; Molina, 2009; Cavalcante, 2010; Molina; Jesus, 2004). No entanto, diante da ampliação de pesquisas e políticas para a área rural, as concepções em torno da política e da prática em contextos de escolarização multisseriada nem sempre foram unânimes e, muitas vezes, acentuaram as adversidades presentes na educação do campo. A pura e simples rejeição ao formato multisseriado, ao invés de contribuir para a educação do campo, do ponto de vista político-pedagógico, oferece espaço para que muitas práticas escolares excludentes, existentes no contexto urbano, sejam reproduzidas na área rural. Por outro lado, essa rejeição também inibe a difusão de práticas pedagógicas alternativas que surgem cotidianamente nas escolas do campo, silenciadas diante da simples negação da multisseriação. Pode-se negar a multisseriação como opção político-financeira e pedagógica, mas não se deve esquecer de que as práticas desenvolvidas em ambientes multisseriados não são de uma única ordem. Assim como em muitos contextos de organização seriada, alternativas, rompimentos e transgressões surgem em virtude de se considerar outros elementos a priori (diferentes do elemento "série").

Apesar disso, é possível encontrar estudos, pesquisas e relatos de experiências sobre as polêmicas, as contradições e a realidade da multisseriação no campo em âmbito brasileiro (Hage, 2005; Hage; AntunesRocha, 2010) e internacional (Little, 1995, 2004; Sigsworth; Solstad, 2005; Pridmore, 2007), detectando, inclusive, avanços na perspectiva de rompimento com a multissérie e tentativas de construção de formatos que tenham outros pressupostos e determinantes na organização da escolarização e do trabalho pedagógico da escola.

O presente artigo tem como objetivo analisar alguns aspectos da organização da escolarização em multisséries, situando-a no Estado de Sergipe e descrevendo o perfil, as concepções e as práticas pedagógicas de professores que atuam em turmas multisseriadas de escolas públicas. Apresenta parte dos resultados da pesquisa "Formas de organização do trabalho pedagógico nas escolas multisseriadas de Sergipe: possibilidades, alternativas e inovações nos tempos e nos espaços escolares", financiada pelo Conselho Nacional de Desenvolvimento Científico e Tecnológico (CNPq). Os dados apresentados são decorrentes da análise estatística de informações disponibilizadas pelo Instituto Nacional de Estudos e Pesquisas Educacionais Anísio Teixeira (Inep), bem como de pesquisas de campo realizadas no Estado de Sergipe.

Constituíram-se sujeitos da pesquisa 127 professores que atuavam em turmas multisseriadas da rede estadual de ensino e de duas redes municipais. 
A análise dos dados possibilitou identificar características a respeito de 131 turmas multisseriadas no Estado, o que representou 9\% das que pertencem à rede pública de ensino de Sergipe. ${ }^{2}$ Como instrumento de coleta de dados, foi aplicado um questionário com questões abertas e fechadas, focalizando quatro categorias de análise relacionadas à multisseriação: organização da escolarização em multisséries; perfil dos docentes; concepções de professores; e práticas pedagógicas.

\section{O quadro da multisseriação no Estado de Sergipe}

Com base em dados disponibilizados pelo Inep, do total de matrículas da educação básica no Brasil, 3\% estavam concentradas em turmas multisseriadas em 2011. No mesmo ano, existiam 57.577 escolas com essa forma de organização, representando 30\% do total de estabelecimentos de educação básica; $76 \%$ das escolas de educação básica do campo; $40 \%$ das de ensino fundamental; $81 \%$ das de ensino fundamental rurais. As escolas brasileiras que possuíam turmas multisseriadas se concentravam na Região Nordeste, responsável por 58\% de todas elas. Além disso, 94\% das turmas multisseriadas de todo o País estavam no campo.

Em 2011, o Estado de Sergipe possuía 823 escolas públicas (99\%) e privadas (1\%) com turmas multisseriadas, sendo que 753 (91\%) estavam localizadas na zona rural e 70 (9\%) na zona urbana. Das 823 escolas com turmas multisseriadas, $95 \%$ eram municipais, $4 \%$ eram estaduais e $1 \%$ era privada.

Sem considerar a dependência administrativa (estadual ou municipal), em 2011 existiam turmas multisseriadas em escolas públicas de 64 (85\%) municípios sergipanos, à exceção de: Amparo de São Francisco, Aracaju, Barra dos Coqueiros, Carmópolis, Divina Pastora, General Maynard, Nossa Senhora de Lourdes, Pedrinhas, Rosário do Catete, Santana de São Francisco e Telha.

Nesse mesmo ano, existiam 27.753 matrículas em turmas multisseriadas no Estado de Sergipe, o que representava $29 \%$ do total de matrículas no ensino fundamental. Em termos de dependência administrativa, das 27.753 matrículas, 96\% (26.739) eram municipais, 3\% (863) estaduais e 1\% (151) privada. Quanto à localização geográfica, 90\% (24.934) eram matrículas em escolas rurais e $10 \%$ (2.819) em escolas urbanas.

Nesse período, na rede estadual de ensino, $16 \%$ das escolas eram rurais e $8 \%$ eram multisseriadas. No que se refere à matrícula, apenas 5\% (9.929) estavam localizadas no campo e 0,4\% (863) em turmas multisseriadas. Portanto, em 2011, a rede estadual de ensino de Sergipe contava com

${ }^{2}$ Das 1.487 turmas multisseriadas existentes em Sergipe, em 2011: 1.355 (91\%) estavam localizadas na zona rural e $132(9 \%)$ na zona urbana. Desse total, $1.418(95 \%)$ eram municipais, 53 (4\%) eram estaduais e 16 (1\%) eram privadas. 29 escolas com 53 turmas multisseriadas, 863 matrículas e 56 funções docentes em 16 municípios: Brejo Grande, Campo do Brito, Canhoba, Carira, Cedro de São João, Frei Paulo, Itabaiana, Japoatã, Laranjeiras, Malhador, Nossa Senhora Aparecida, Nossa Senhora do Socorro, Riachão do Dantas, Ribeirópolis, São Cristóvão e Simão Dias. Das 29 escolas, 7 estavam localizadas na zona urbana e 22 na zona rural. 
Quanto às 863 matrículas vinculadas à rede estadual de ensino, 59\% (512) localizavam-se em escolas da área rural e 41\% (351) da área urbana. As matrículas concentravam-se nos seguintes municípios: Simão Dias (299), Nossa Senhora do Socorro (101) e Itabaiana (73).

Os dados também indicam que $88 \%$ dos municípios com turmas multisseriadas na rede estadual de ensino possuíam entre 1 e 100 alunos matriculados.

No que se refere especificamente às redes municipais de ensino, existiam turmas multisseriadas em escolas de 63 municípios (84\%). Considerando-se as 783 escolas municipais que possuem turmas multisseriadas, dos 63 municípios, 93\% estavam localizadas no campo.

A maior parte dos municípios (59\%) com essa forma de organização possuía entre 1 e 10 escolas com turmas multisseriadas, $22 \%$ deles possuíam entre 11 e 20 e 19\% possuíam 21 ou mais. Os municípios com maior quantitativo de escolas com turmas multisseriadas eram: Lagarto (56), Itabaiana (39), Itaporanga D'ajuda (38), Carira (33) e Itabaianinha (31), sendo responsáveis por 25\% das escolas com multisseriação no Estado.

A análise da multisseriação nas redes municipais de ensino permite ainda visualizar algumas especificidades, entre elas, o fato de que, em 42 municípios (67\%), 100\% das escolas com turmas multisseriadas estavam localizadas no campo e, em apenas um município (Nossa Senhora do Socorro), 100\% delas estavam localizadas, em 2011, na zona urbana. Em São Cristóvão, a maioria das escolas concentrava-se na zona urbana (14 de 15). Em 18 municípios analisados, a maior parte das unidades de ensino estava localizada na área rural, com existência de uma ou mais escolas na área urbana. Por último, em apenas um município, 50\% das escolas estavam localizadas no campo e 50\%, na zona urbana.

No que se refere às matrículas das redes municipais de ensino, a maior parte dos municípios (27\%) possuía entre 101 e 250 matrículas em turmas multisseriadas.

Existiam quatro municípios com mais de 1.000 matrículas em turmas multisseriadas: Lagarto (3.708), Itabaiana (1.555), Itaporanga D'ajuda (1.073) e Aquidabã (1.026). Esses municípios, juntos, concentravam 27\% das matrículas em turmas multisseriadas municipais do Estado.

A análise dos dados do Inep indica a relevância de estudos sobre a multisseriação no Estado de Sergipe, bem como da formulação de políticas públicas na área. Somada à análise de dados estatísticos, a pesquisa de campo, por meio da aplicação de questionários, apreendeu aspectos qualitativos importantes sobre o perfil, as concepções e as práticas pedagógicas dos professores que atuam em turmas multisseriadas, conforme explicitado a seguir.

\section{Perfil dos professores que atuam em turmas multisseriadas}

Dos 127 professores analisados, no que se refere ao vínculo profissional, $66 \%$ eram concursados e $32 \%$ contratados. 
Dos participantes da pesquisa, a grande maioria (56\%) morava na cidade, $26 \%$ no mesmo povoado onde está localizada a escola e $18 \%$ em povoado diferente.

Quanto à história escolar dos professores, 49\% estudaram em escolas da cidade, $46 \%$ nas do campo e $4 \%$ em ambas.

No que se refere ao tipo de escola, a maioria dos docentes (75\%) estudou em escolas seriadas e apenas $18 \%$ estudaram exclusivamente em escolas multisseriadas.

Dos professores que atuavam em turmas multisseriadas, 46\% estavam há menos de um ano à frente dessa forma de organização da escolarização e 20\% atuavam há menos de um ano nas escolas do campo.

Para a grande maioria dos docentes (64\%), trabalhar com a multisseriação não foi uma escolha pessoal, ao passo que 14\% fizeram essa opção. No entanto, chama a atenção que, dos professores que indicaram ser essa uma escolha individual, dois moram na cidade e um no campo.

A análise dos dados da pesquisa de campo mostra que há um grande quantitativo de professores (32\%) que atua na área rural e na multisseriação com vínculos transitórios, o que pode indicar pouca preocupação com uma política consistente ou mesmo a inexistência de uma política de incentivo ao trabalho do professor no campo. Essa condição inviabiliza e fragiliza políticas de formação continuada, pois o grupo de trabalhadores se altera de tempos em tempos. Um sistema de ensino com grande número de profissionais no campo detentores de vínculos transitórios perde em capacidade de planejamento de uma política de formação continuada de professores. Política de formação continuada é entendida como a abrangência de vários elementos, entre eles, a formação no interior da própria escola, com os coletivos de profissionais daquela unidade de ensino e suas relações com outras instituições e sujeitos, e não como processos esparsos de qualificação, eventos em grande escala, acontecimentos esporádicos no início do ano letivo, cursos promovidos unilateralmente por parte das secretarias de educação.

É visível a dificuldade de implantação de um projeto de formação continuada num cenário em que o grupo de professores não apresenta vínculo nem com a rede nem com a realidade do campo. Esses dados reforçam a pouca preocupação política com a escola da área rural, embora a experiência empírica evidencie a quase inexistência de uma política concreta de formação continuada de professores, não apenas no campo, mas nas redes como um todo.

A questão do vínculo articula-se à possibilidade de dedicação exclusiva do docente, inclusive numa mesma rede, até numa mesma escola, de modo que seja viável o investimento em projetos pedagógicos e comunitários na própria unidade de ensino, além de uma discussão mais efetiva sobre a carga horária do professor destinada a estudos, planejamento, reuniões, projetos, formação etc. Daí a importância de se pensar em planos de carreira do magistério mais efetivos, que privilegiem o trabalho do professor em apenas uma unidade de ensino - possibilitando o desenvolvimento de ações mais duradouras em termos de projeto coletivo da escola e 
de processos formativos - e, especificamente em relação às escolas do campo, que incorporem, de alguma forma, incentivos relativos ao trabalho nas unidades de ensino da área rural. Há evidências empíricas de que, às vezes, a atuação em determinados níveis e modalidades de ensino e em certas regiões ou escolas é vista como um fator de punição do professor, por exemplo, na educação infantil, na educação de jovens e adultos, na educação do campo e em escolas multisseriadas. Por isso, no processo de escolha de turmas, geralmente, privilegiam-se: o ensino regular, o ensino fundamental, a zona urbana, as escolas centrais e as escolas seriadas (em oposição às multisseriadas). Diante da ausência de incentivos ao trabalho docente no campo, com previsão de investimentos na materialidade da escola e na formação continuada, a opção individual por atuar nas escolas da área rural e, particularmente, naquelas que atualmente se organizam por meio de multisséries é baixa, de modo que geralmente a secretaria de educação designa os professores, e justamente por isso tende a designar os contratados.

Mais uma vez, deve-se destacar a importância de uma decisão política acerca da educação do campo e das turmas multisseriadas no município. Se elas são residuais quantitativamente, não o são do ponto de vista das comunidades nas quais estão inseridas. As escolas são, na grande maioria das vezes, o único espaço comunitário existente.

A pesquisa indicou que os professores que atuavam nas escolas do campo e nas turmas multisseriadas, em sua maior parte, moravam e estudaram na cidade. Embora isso não possa ser entendido de forma negativa para o desenvolvimento de um bom trabalho nas unidades de ensino da área rural, no mínimo, pode indicar - conforme a pesquisa reduzidos vínculos do professor com as questões e com a vida no campo. Esse tipo de informação indica também que a vivência do educador como aluno na escola do campo ou na multisseriada poderia influenciar em suas concepções e práticas a depender das experiências e das lembranças que tem do seu passado. Isso também pode levar a reproduções de modelos já vivenciados como aluno ou a rompimentos com aqueles que se mostraram negativos em sua experiência escolar.

É necessário, portanto, investimento na formação continuada, a fim de que o professor possa (re)conhecer a população e seus modos de vida no campo. Tendo isso como pressuposto, será mais fácil compreender a necessidade de investimento em outro tipo de organização, para além da multisseriação.

\section{A organização da escolarização em multisséries no Estado de Sergipe}

A multisseriação não pode ser tratada de forma homogênea - uma análise mais profunda possibilita verificar a sua complexidade. Os estudos de caso analisados indicaram a existência de 15 formatos de multisseriação no Estado, sendo aqueles que abrangem 2 anos/séries os mais numerosos 
(33\%), ao lado dos formatos que envolvem 3 anos/séries. Há, no entanto, 13\% das turmas organizadas no formato que abrange 5 anos/séries.

Das 131 turmas analisadas, há concentração no formato multisseriado "4\% $/ 5^{\circ "}(20 \%)$ e "1\%/2o" (17\%).

\section{Tabela 1 - Quantidade de Turmas por Tipo de Multisseriação - Sergipe -2012}

\begin{tabular}{|c|c|c|}
\hline Tipo de turma & $\begin{array}{c}\text { Quantidade de } \\
\text { turma }\end{array}$ & $\%$ \\
\hline Pré/ $1^{\circ}$ & 9 & 7 \\
\hline Pré/ $1^{\circ} / 2^{\circ}$ & 9 & 7 \\
\hline Pré $/ 1^{\circ} / 2^{\circ} / 3^{\circ}$ & 2 & 2 \\
\hline Pré/ $1 \% / 2^{\circ} / 3^{\circ} / 4^{\circ}$ & 2 & 2 \\
\hline Pré/ $1^{\circ} / 3^{\circ}$ & 1 & 1 \\
\hline $1^{\circ} / 2^{\circ}$ & 22 & 17 \\
\hline $1^{\circ} / 2^{\circ} / 3^{\circ}$ & 14 & 11 \\
\hline $1^{\circ} / 2^{\circ} / 3^{\circ} / 4^{\circ}$ & 3 & 2 \\
\hline $1^{\circ} / 2^{\circ} / 3^{\circ} / 4^{\circ} / 5^{\circ}$ & 8 & 6 \\
\hline $2^{\circ} / 3^{\circ}$ & 6 & 5 \\
\hline $2^{\circ} / 3^{\circ} / 4^{\circ} / 5^{\circ}$ & 1 & 1 \\
\hline $2^{\circ} / 4^{\circ} / 5^{\circ}$ & 1 & 1 \\
\hline $3^{\circ} / 4^{\circ}$ & 14 & 11 \\
\hline $3^{\circ} / 4^{\circ} / 5^{\circ}$ & 13 & 10 \\
\hline $4^{\circ} / 5^{\circ}$ & 26 & 20 \\
\hline Total & 131 & 100 \\
\hline
\end{tabular}

Fonte: Pesquisa de Campo - Sergipe, 2012. Organizado pela autora.

Chama a atenção a existência de turmas multisseriadas envolvendo alunos matriculados na educação infantil e no ensino fundamental. Essa junção representa $18 \%$ das turmas analisadas, havendo cinco formatos possíveis - podendo-se agrupar do pré ao $4^{\circ}$ ano do ensino fundamental.

Um tipo de multisseriação diferenciada encontrada refere-se a dois formatos com ausência de um ano/série, qual seja: formato "pré/1\%/3"; "2\% $/ 4^{\circ} / 5^{\circ} "$.

Analisando a variação de idade por tipo de turma multisseriada, deseja-se chamar a atenção para a distorção idade-série ainda muito presente na realidade apresentada. As turmas com formato multisseriado do $1^{\circ}$ ao $5^{\circ}$ ano, por exemplo, podem ter alunos de, no mínimo, 5 anos e, no máximo, 16 anos, apresentando um distorção idade-série de até 6 anos. Isso significa que, se o professor trabalha com dois anos/séries, seu trabalho ocorre com alunos pertencentes a faixas etárias muito diversas, envolvendo 
até 12 idades diferentes numa mesma turma. Ressalta-se que essa realidade não é privilégio apenas da escolarização organizada em multisséries, ela é antes reflexo da própria organização seriada, predominante nos sistemas de ensino brasileiros e cujos princípios acarretam processos de exclusão, entre eles, a reprovação continuada que leva à distorção idade-série. Essa condição leva à naturalização de salas de aula com alunos pertencentes a 12 idades distintas, geralmente sob um mesmo tipo de intervenção pedagógica.

Analisou-se também a quantidade de alunos por tipo de turma multisseriada, identificando-se turmas com no mínimo 10 e no máximo 40 discentes, um quantitativo muito alto para o trabalho com crianças no primeiro segmento do ensino fundamental. A exemplo da enturmação de $1^{\circ}$ ao $5^{\circ}$ ano, o professor trabalha com 28 alunos de inúmeras idades.

É perceptível, portanto, a ausência de critérios na organização das turmas multisseriadas, para além da seriação. Há um desejo de que a multisseriação avance para um olhar mais atento aos sujeitos da educação e, inclusive, elimine o fardo nominal que carrega, estreitamente articulado à seriação. No entanto, os dados da realidade das turmas pesquisadas mostraram que as opções político-administrativas ainda estão muito arraigadas na lógica da seriação e limitam as opções pedagógicas a serem desencadeadas no âmbito dos sistemas de ensino e pelos próprios professores.

Viu-se que a multisseriação, na maior parte dos casos, não opera pedagogicamente, e sim administrativa e financeiramente - muitas vezes opera antipedagogicamente, tendo em vista as condições precárias de várias escolas multisseriadas, a começar pela quase falta de lógica na organização das multisséries, considerando-se apenas a necessidade administrativa de juntar alunos de diferentes anos/séries.

A multisseriação pressupõe a organização de turmas envolvendo alunos matriculados em diferentes séries/anos. No Brasil, as turmas, quando administrativamente são formadas, consideram apenas o elemento série/ ano. ${ }^{3}$ No entanto, há que se destacar que a multissérie se articula à multiidade, tendo em vista que, ao organizar as turmas com base nas séries/anos, são carregadas todas as contradições da lógica seriada: evasão, entrada tardia na escola, reprovação e distorção idade-série. A própria seriação, portanto, articula-se à multi-idade, já que também desconsidera as idades, priorizando a série/ano dos sujeitos na organização das turmas.

Assim, a adoção da multisseriação, geralmente, é feita pela mera transposição da seriação a contextos multi-idades. Devido à reprodução das práticas seriadas, ocorre uma duplicação ou mesmo uma quintuplicação do trabalho docente seriado. Ou seja, devido ao histórico da reprovação, do atraso no início da escolarização e mesmo da evasão, turmas multisseriadas do $1^{\circ}$ ao $5^{\circ}$ ano, que, pela lógica do fluxo regular idade/série, atenderiam alunos de 6 a 10 anos, passam a atender alunos de inúmeras idades.

Uma análise que considere apenas a multisseriação como junção de anos/séries pode não detectar seu nível de complexidade no Brasil, um país herdeiro de muitas práticas de seleção, exclusão e reprovação. Daí a importância de compreender as opções que os gestores fazem ao organizar
${ }^{3}$ Cabe destacar que no multigrade teaching, em alguns países desenvolvidos, o elemento a priori continua a ser a idade do aluno, assim como no monograde teaching (Little, 2004; Pridmore, 2007). 
o formato da multisseriação, muitas vezes sem qualquer associação com opções pedagógicas. ${ }^{4}$

O que se vê nos sistemas de ensino analisados, assim como em todo o Brasil, via de regra, é que a idade, como elemento a priori na organização da escolarização, aparece apenas como pré-requisito para o ingresso da criança no ensino fundamental, aos seis anos de idade. Após isso, apesar das várias possibilidades que a legislação educacional brasileira oferece aos sistemas de ensino, seja do ponto de vista da organização da escolarização obrigatória, seja do ponto de vista das formas de progressão e de avaliação dos alunos, a idade é fator secundário na maioria das vezes. Isso faz com que seja possível - e natural para muitos - a ocorrência de enturmações envolvendo sujeitos de 12 idades distintas, conforme observado nos estudos de caso, inibindo trabalhos pedagógicos que priorizem os tempos de vida dos alunos, já que são secundarizados ou mesmo desconsiderados já de início pelos próprios sistemas de ensino. Achar natural a enturmação de alunos de 5 a 16 anos, por exemplo, é, no mínimo, ser cúmplice de um processo de desumanização que já se arrasta por muito tempo na educação brasileira. No entanto, situações como esta já estão tão naturalizadas que muitos encontram saída na pura e simples defesa da necessidade da reprovação, sem compreender sua gênese excludente e seletiva. Outras saídas recorrem à defesa da eliminação da multisseriação associada à política de nucleação e fechamento de escolas do campo.

Portanto, dizer que a multisseriação é a principal forma de agrupamento numa determinada escola não significa necessariamente a mistura de alunos de várias séries/idades numa mesma atividade. Significa, na maior parte das vezes, mistura de idades, caso haja alunos com histórico de reprovação, por exemplo, mas tomando a série como eixo central. Contudo, numa mesma turma, o professor tem trabalhado com crianças e jovens ao mesmo tempo, o que evidencia um grave problema não apenas de ordem metodológica por parte do docente, ênfase que muitas vezes tem sido dada à prática dos professores em turmas multisseriadas. Casos como esse devem ser utilizados para que o sistema repense seu projeto educativo como um todo e tome uma decisão política para eliminar esses processos altamente desumanizadores e excludentes.

Essa perversidade em tratar as questões da área educacional apenas sob o prisma do aspecto administrativo vem naturalizando e legitimando enturmações de alunos provenientes da educação infantil e do ensino fundamental. Do ponto de vista legal, vale lembrar que as Diretrizes Complementares, Normas e Princípios para o Desenvolvimento de Políticas Públicas de Atendimento da Educação Básica do Campo (Brasil, 2008) proíbem o agrupamento de crianças da educação infantil e do ensino fundamental. Independentemente da questão legal, o mais importante a destacar é que os agrupamentos multisseriados que envolvem a educação infantil e o ensino fundamental, como se viu nos estudos de casos, são os mais diversos e podem levar a uma multisseriação que abarca idades muito diferenciadas.
A exemplo de países onde multigrade teaching é uma opçã pedagógica (Little, 2004). 
Além disso, outro fator a considerar nesse tipo de agrupamento é o trabalho e a prática do professor diante das necessidades e especificidades da educação infantil, tendo em vista que, diante de empecilhos, dificuldades e barreiras quanto à materialidade e às condições do trabalho docente, os processos de socialização e de comunicação, incluindo-se o brincar, são simplesmente negados, desconsiderados e negligenciados em nome do desenvolvimento das linguagens simbólicas (escrita, matemática etc). Ou seja, ante as condições objetivas, é quase certo que a multisseriação, assim como tem feito a seriação, negará aos sujeitos da educação, pertencentes a tempos de vida específicos, o direito de se desenvolverem plenamente diante de suas condições biológicas, culturais e sociais.

Nos casos analisados, não se viu nenhuma iniciativa de, em face de uma necessidade administrativa de juntar alunos, avançar para reflexões e propostas pedagógicas que considerem, inclusive, o quesito idade, ou melhor, o tempo de vida dos sujeitos - infância, pré-adolescência, adolescência etc (Lima, 2002; Arroyo, 1999; Parente, 2010).

Diante dessas considerações, é essencial destacar o papel políticopedagógico e decisório dos sistemas de ensino na organização dos tempos de escolarização. A multisseriação não pode ser interpretada como uma simples decisão política de minimizar custos.

É preciso partir do pressuposto do direito à educação e avançar, política e pedagogicamente, para a construção de formas de organização da escolarização mais humanas e humanizadoras (Arroyo, 2011), que busquem romper com as muitas naturalizações que persistem na área educacional.

Deseja-se destacar o peso das construções temporais validadas e legitimadas pelos sistemas de ensino, engessando, inibindo e limitando o fazer-docente, as quais, inclusive, parecem sugerir que qualquer movimento contrário pode significar processos de transgressão, interpretados como ataque ao que já está consolidado, estruturado, solidificado material e simbolicamente. Com a multisseriação, é justamente isso o que ocorre.

É preciso, portanto, que os sistemas de ensino tenham a coragem de construir, coletivamente, projetos de educação que considerem a temática dos tempos de vida dos sujeitos. Os estudos de caso evidenciaram a completa desconsideração dessa temática nos poucos momentos de trabalho coletivo existentes.

\section{Concepções de professores que atuam em turmas multisseriadas}

A análise da concepção de professores que atuam em turmas multisseriadas considerará alguns aspectos principais: causas da multisseriação; aspectos pedagógicos positivos e negativos; extinção da multisseriação; vínculos entre seriação e multisseriação; perfil docente; gosto para atuar em turmas multisseriadas.

A pesquisa evidenciou clareza na visão dos professores em relação à existência da multisseriação, uma vez que busca atender a populações do campo historicamente à margem da educação, regiões pouco povoadas e 
mais afastadas e um número reduzido de alunos por região/escola/turma. Concebem a multisseriação, portanto, como uma forma de atendimento diante de uma necessidade. A existência da multisseriação impede o fechamento de escolas e evita que o aluno tenha que viajar longas distâncias ou mesmo estudar em outro povoado diferente daquele onde vive. Por outro lado, apesar de a multisseriação associar-se à questão do acesso à educação, alguns professores indicaram o lado trágico dessa forma de organização: quando a utilizam em lugar de se resolver problemas advindos do próprio sistema, como é o caso da falta de professores ou mesmo da falta de espaço para mais salas de aula. Ou seja, muitas vezes a multisseriação é resultado da junção de duas ou mais turmas com número razoável de alunos, levando-se a uma economia no quadro de professores.

Dos participantes da pesquisa, 70\% indicaram a existência de aspectos pedagógicos positivos na multisseriação, entre eles: interação, socialização e trocas de experiências entre alunos matriculados em diferentes séries. Além disso, elencou-se também o fato de que a multisseriação possibilita ao aluno frequentar a escola em sua própria comunidade. Há ainda a percepção dos professores de que, independentemente da matrícula em uma série específica, a multisseriação possibilita compreender que "existem alunos que estão no mesmo nível de aprendizagem". Outra professora destaca que "os aspectos positivos não são decorrentes da multisseriação e sim por conseguirmos torná-los positivos dentro da prática pedagógica".

Além disso, os docentes pesquisados apontaram dois aspectos importantes: os alunos mais novos aprendem com os mais velhos e os alunos mais velhos ensinam os mais novos. Esse aprendizado também ocorre sem referência direta à idade: quem sabe mais ensina quem sabe menos.

Por isso, uma professora respondeu que "quando não há uma diferenciação muito grande de idade, toda forma de socialização é positiva para o conhecimento".

Apesar dos aspectos positivos citados, $71 \%$ dos professores pesquisados também apontaram aspectos negativos na multisseriação, quais sejam: falta de material pedagógico adequado, falta de apoio pedagógico, espaço físico inadequado, falta de apoio e incentivo por parte do sistema, baixo desempenho por parte dos professores, necessidade de acompanhamento individual para o aluno, desigualdades de desempenho em relação aos discentes, quantidade de séries numa mesma turma, falta de tempo para planejamento, distorção idade-série, diversos níveis de aprendizagem numa mesma turma.

Sobre a possibilidade de eliminação da multisseriação, 32\% dos professores informaram que ela deveria deixar de existir, tendo em vista que: "tornaria o nosso trabalho menos difícil"; porque só se trabalharia "um conteúdo e não dois ou mais"; "porque nas turmas seriadas a aprendizagem é mais proveitosa"; "quanto menor o número de alunos, melhor seria o desenvolvimento do processo de aprendizagem"; porque a seriação "facilita não só o desempenho do aluno como também ajuda no melhor planejamento do professor, visando, assim, uma melhor aprendizagem para os alunos". 
No entanto, 61\% defenderam que a multisseriação não deve ser eliminada, já que: "é necessário que continue existindo para que a comunidade rural seja beneficiada de maneira digna, de forma que possa usufruir de um ensino de qualidade sem precisar retirar seu alunado do campo antes do tempo"; "para não acabar com as escolas do campo, pois elas são referência para os membros de suas respectivas comunidades"; "porque a esperança em modificar vem do campo, modificar no sentido pedagógico, político e social"; e porque com a "extinção da multisseriação, os alunos deverão deslocar-se para os centros urbanos", o que é dispendioso e cansativo.

Quando questionada sobre os possíveis vínculos entre seriação e multisseriação, a grande maioria dos professores (69\%) informou que são trabalhos distintos, já que na multisseriação: "além dos diferentes níveis, trabalhamos também com diferentes séries"; porque é necessário "compromisso, responsabilidade, dedicação e profissionalização" de quem assume turmas multisseriadas; porque é necessário "fazer de dois a três planejamentos para que se tenha proveito na aprendizagem do aluno"; "porque são vários tipos de avaliação, muito mais material didático para observar, ler, carregar".

Já 23\% dos professores informaram haver similaridades com o trabalho nas duas formas de organização da escolarização, tendo em vista que, tanto nas turmas seriadas como nas multisseriadas, existem "alunos com diferentes níveis de aprendizagem". Tais respostas indicam que a diferença talvez seja no nível de complexificação do trabalho do professor: seriação sujeitos diferentes matriculados na mesma série; multisseriação - sujeitos diferentes matriculados em diferentes séries.

A maior parte dos professores (52\%) elencou que é preciso ter características específicas para atuar na multisseriação, quais sejam: ser dinâmico, ter dedicação, responsabilidade, comprometimento, agilidade e criatividade e ser pesquisador. Muitos alegam que tais qualidades são necessárias na multisseriação, "porque os alunos são de faixas etárias diferenciadas"; porque o professor "precisa ter a habilidade da convivência com diferentes níveis de aprendizagem"; "para poder controlar duas turmas ou três turmas diferentes". Por fim, um professor indicou que essas qualidades são fundamentais, tendo em vista que "deveria atuar na multisseriada quem tem mais habilidades para esta área". Apesar disso, um número também significativo de docentes (44\%) respondeu que não é preciso ter qualidades específicas para atuar na multisseriação, já que: "em qualquer turma o professor deve trabalhar com compromisso e dedicação"; "é um trabalho em sala de aula como na sala seriada, o que vai diferenciar é que esse professor vai precisar ter mais jogo de cintura para administrar essas turmas". Apesar disso, uma professora, ao ressaltar sua crítica em relação à multisseriação, alerta que: "tanto faz, é difícil para qualquer docente atuar numa turma multisseriada; pode ser o melhor profissional, não vai conseguir o seu objetivo".

Dos professores que participaram da pesquisa, 46\% afirmaram que não gostam de trabalhar com a multisseriação, tendo em vista que é um trabalho 
desgastante, envolve sujeitos com diferentes níveis de aprendizagem, os alunos não aprendem bem e "dar aula para a turma seriada é melhor". Uma das professoras relata: "não fui preparada para isso, me sinto angustiada; para mim, eu nunca alcanço minhas metas, embora seja elogiada".

Por outro lado, $47 \%$ dos professores responderam que gostam de trabalhar na multisseriação, principalmente por ser um trabalho desafiante. Apesar de gostar, uma professora afirma que, "como escolha profissional, preferiria a sala seriada".

Vale destacar a resposta de uma professora: "trabalho sempre o que é preciso na série de cada um". Outra docente relata: "toda turma, seja ela qual for, é multisseriada". A posição dessas professoras revela o quanto as concepções dos profissionais da educação estão arraigadas na lógica da seriação.

Analisando os dados, afere-se que, em geral, os docentes compreendem os motivos que levam a escola a se organizar em multisséries, inclusive associando-as à ampliação das oportunidades aos sujeitos do campo. Dessa forma, a extinção da multisseriação significaria a eliminação da própria educação do campo. No entanto, essa compreensão não significa a aceitação da multisseriação por parte dos professores.

A não aceitação da multisseriação vincula-se ao desejo de transformar a escola multisseriada do campo em uma escola seriada urbana, reforçando o que autores como Arroyo (2010) e Hage (2005) já afirmavam em suas pesquisas e reflexões.

Apesar disso, há indícios de que, se houver investimento num processo formativo e na materialidade da escola, é possível que sejam criados espaços para a construção de novas concepções acerca da função social e da organização da unidade de ensino.

A pesquisa empírica evidenciou que a multisseriação, na maioria das vezes, é uma reprodução da seriação. Aqueles professores que apresentam um olhar mais sensível aos sujeitos da educação acabam por entender que, na lógica da seriação, as diferenças também existem, e daí a compreensão de que toda turma "é multisseriada", como relatou uma professora. $\mathrm{Na}$ verdade, o mais sensato seria deixar a vertente da seriação de lado e compreender que toda turma "é diferente", pois possui sujeitos diferentes, seja numa turma seriada ou multisseriada. Portanto, mais uma vez, este estudo reforça a importância de considerar a multisseriação no âmbito de uma política educacional do sistema como um todo, incorporando questões relativas à formação dos professores, às condições de trabalho docente, à infraestrutura das escolas, ao currículo escolar e à organização dos tempos e espaços educativos, elementos que devem fazer parte de um projeto de educação amplamente debatido com os diferentes segmentos da sociedade. A pesquisa empírica detectou uma visão muito limitada acerca da função social da escola e, quando ampliada por parte de alguns professores, eles não conseguiram avançar para além de outras concepções postas pelo sistema seriado, reflexo do processo de naturalização que paira na área de educação. 


\section{Práticas pedagógicas de professores que atuam em turmas multisseriadas}

O instrumento de coleta de dados buscou captar, entre outros: planejamento do professor; formas de enturmação; organização espacial dos alunos; espaços utilizados para o desenvolvimento do trabalho pedagógico; materiais utilizados como referência.

Quando questionados acerca da forma como fazem seu planejamento, a maioria dos professores (53\%) toma o ano/série do aluno como referência básica, mas pensa também em outros aspectos. Esses docentes assim se justificam: "planejo pensando no ano/série, porém, vou além"; "porque nem sempre o ano/série reflete as verdadeiras necessidades dos alunos"; "além da série do aluno, devemos pensar no seu conhecimento prévio e na realidade do aluno"; é preciso pensar "na dificuldade e habilidade de cada aluno"; "porque a turma não é homogênea". Outra professora destaca que, "por ser uma turma multisseriada, tenho que buscar uma forma de facilitar a minha prática para que haja um melhor aprendizado, sem esquecer a turma que cada um está"; "devemos levar em consideração a faixa etária dos alunos e o meio no qual ele está inserido".

Os docentes foram questionados sobre a forma como trabalham diariamente na maior parte do tempo e como enturmam os alunos: a maioria (32\%) trabalha coletivamente sem a divisão da turma em grupos menores. Essa prática é justificada pelos professores: "porque tem tema que permite a junção das duas séries"; "porque um ajuda o outro nas dificuldades"; "todos estão na sala de aula para aprender e não existem diferenças, o aluno que sabe mais que o outro deve ajudar"; "é importante a socialização"; "porque acho melhor não diferenciar esses alunos partindo da visão da interação do saber, da descoberta do novo e da participação atuante de todos os alunos". Outro grupo de professores (27\%) respondeu que enturma os discentes conforme o ano/série em que estão matriculados porque "se torna mais fácil aplicar o conteúdo, orientar e tentar verificar a aprendizagem e dificuldade de cada um dos alunos"; "para tentar facilitar o trabalho"; "pela facilidade de aplicar o conteúdo"; "porque aquele que tem mais facilidade de aprendizagem ajuda o mais fraco".

No que se refere à forma de organização espacial dos discentes em sala de aula, a maioria dos professores (37\%) informou que seus alunos ficam, grande parte do tempo, em semicírculo/círculo, pois ajuda na visualização da turma, sua integração e noção de pertencimento ao grupo e se rompe com a hierarquização. Essa prática é justificada pelos docentes: "porque eles prestam mais atenção na explicação do professor"; "para que haja maior interação entre professor e aluno, facilitando o aprendizado"; "é importante que tenha interação entre eles e que um visualize o outro"; pois assim "acompanho com mais facilidade"; porque "fica melhor de se trabalhar, o ângulo é melhor, aumenta o espaço e fica mais confortável".

Já 25\% dos participantes da pesquisa informaram que seus alunos ficam dispostos em fileiras, justificando que assim o fazem por "falta de 
espaço"; porque "conversam menos e aprendem mais"; porque os próprios alunos preferem dessa forma.

No que se refere aos espaços para o desenvolvimento da prática pedagógica, $60 \%$ dos professores informaram que, na maior parte do tempo, desenvolvem atividades dentro da sala de aula. Quando questionados se utilizam outros espaços além da sala de aula, a maioria (87\%) respondeu positivamente, o que foi justificado de diferentes formas, entre as quais: "para quebrar a rotina e levar o aluno a perceber que a aprendizagem está em todo lugar"; "o professor de uma escola do campo tem oportunidade de utilizar o espaço ao redor da escola para dinamizar suas aulas".

Quanto aos materiais utilizados pelos docentes para o desenvolvimento da prática pedagógica, $44 \%$ dos professores elaboram as próprias atividades para seus alunos. Conforme relata uma professora: "sinto dificuldade de trabalhar com três tipos de livros diferentes ao mesmo tempo". Outros docentes informaram que "os livros didáticos não refletem a realidade do nosso aluno do campo" e que as atividades "são elaboradas de acordo com o nível de conhecimento para facilitar o aprendizado do aluno".

A pesquisa de campo demonstrou uma vez mais que o aspecto administrativo da multisseriação atua como elemento inibidor da prática docente. Há mostras de que os professores possuem sensibilidade em relação ao aprendizado dos alunos, porém, as respostas não demonstram ainda nenhuma iniciativa explícita de rompimento com a série, e, em outras vezes, são evidentes algumas ações que legitimam e validam práticas excludentes.

Dos casos estudados, chama a atenção o fato de nenhum professor fazer menção à organização do trabalho em sala de aula, tomando-se como referência a faixa etária dos alunos, o que evidencia a naturalização da distorção idade/série/ano existente nas escolas. A enturmação com base na idade, apesar de anunciada como alternativa no questionário aplicado, não foi indicada por nenhum professor. Isso evidencia a necessidade de um trabalho de formação dos professores considerando temáticas imprescindíveis, tais como: currículo, organização do trabalho pedagógico e tempos de vida dos sujeitos educativos. Ressalta-se mais uma vez que a multisseriação, administrativamente, faz enturmações de 4 a 16 anos, por exemplo. Com base na pesquisa empírica, evidenciou-se que na sala de aula, por meio da prática docente, não há iniciativas de rompimento com essa lógica.

Apesar disso, há indícios de que sejam viáveis alterações nesse contexto, a médio e a longo prazo, caso haja investimentos do sistema numa política de formação docente, com vistas a trazer para o cotidiano escolar questionamentos acerca dos diferentes elementos da organização do trabalho pedagógico. Porém, uma política de formação docente deve articular-se, necessariamente, à oferta de condições de trabalho justas e dignas para os professores, inclusive com investimentos na materialidade das escolas.

A questão do espaço escolar, no que se refere à educação do campo, é primordial. As respostas dos professores indicaram dois aspectos 
principais: primeiro, a infraestrutura da escola, muitas vezes inadequada, restringe o trabalho pedagógico; segundo, a dificuldade de compreensão de que o desenvolvimento da criança e do adolescente deve considerar vários aspectos além da alfabetização e, para isso, deve utilizar diferentes práticas, metodologias e espaços, para além do caderno, da carteira e da sala de aula. Em algumas respostas, percebe-se um esforço no rompimento com a organização espacial tradicional de enfileiramento de carteiras, unidirecional, bem como no uso de outros espaços para o desenvolvimento dos alunos. No entanto, há certa fragilidade nas motivações desta prática, que soa apenas como distração ou complemento da ação na sala de aula. É preciso propiciar espaços de discussão entre os professores, a fim de que identifiquem as motivações e razões de suas práticas. Mais importante do que o uso deste ou daquele espaço, são as razões de se fazer isso. Sem esse tipo de reflexão, dificilmente haverá mobilização e reivindicação de espaços que a própria escola do campo vem requerendo para seu fortalecimento.

\section{Considerações finais}

Em síntese, o presente artigo trouxe algumas constatações que podem contribuir para reflexões, políticas e formação de professores na área da educação do campo, sobretudo em escolas que possuem organização da escolarização em formatos multisseriados:

- a necessidade administrativa e financeira de organizar turmas multisseriadas deve associar-se à promoção e à garantia do direito à educação de todos;

- sendo a educação um direito de todos, qualquer formato de organização da escolarização deve ser promovido aliando-se os aspectos político, administrativo e financeiro ao aspecto pedagógico, sob pena de promover uma educação empobrecida e excludente;

- a organização da escolarização em multisséries, como as que foram estudadas em Sergipe, não pode ser vista como uma organização única; ela possui diferentes formas, mas tem como pressuposto central a junção de anos/séries, desconsiderando o elemento idade, o que tem gerado enturmações de alunos com idades muito diversas, sem que a intervenção pedagógica se altere em função da diversidade de sujeitos e tempos de vida;

- diante do perfil dos professores que atuam em turmas multisseriadas, evidencia-se a necessidade de um olhar mais atento aos sujeitos do campo para que, a partir disso, a intervenção pedagógica possa ser devidamente construída, assim como novas lógicas que ultrapassem os aspectos administrativos de enturmação;

- as concepções e práticas de professores que atuam em turmas multisseriadas evidenciam ainda que o trabalho docente 
está engessado por determinações externas e por barreiras administrativas, inibindo novas reflexões e práticas que rompam com as lógicas tradicionais da seriação, permeadas de elementos excludentes.

Por fim, deseja-se ressaltar a importância da disseminação de pesquisas, práticas e experiências que tratem da multisseriação, deixando vir à tona avanços e perspectivas na oferta de uma educação de qualidade a todos.

\section{Referências bibliográficas}

ARROYO, M. G.; CALDART, Roseli Salete; MOLINA, Monica Castagna (Org.). Por uma educação do campo. Petrópolis, RJ: Vozes, 2009.

ARROYO, M. G. Humanização docente: heranças, ofícios e trajetórias de educadores/as. In: PARENTE, C. M. D.; PARENTE, J. M. (Org.). Avaliação, política e gestão da educação. São Cristóvão: Ed. da UFS, 2011. p. 21-38.

ARROYO, M. G. Escola: terra de direitos. In: HAGE, Salomão Mufarrej; ANTUNES-ROCHA, Maria Isabel (Org.). Escola de direito: reinventando a escola multisseriada. Belo Horizonte: Autêntica, 2010. p. 9-14.

ARROYO, M. G. Ciclos de Desenvolvimento Humano e formação de educadores. Educação e Sociedade, Campinas, v. 20, n. 68, p. 143-162, dez. 1999.

BRASIL. Instituto Nacional de Estudos e Pesquisas Educacionais Anísio Teixeira (Inep). Sinopse Estatística da Educação Básica. 2011. Disponível em: <http://portal.inep.gov.br/basica-censo-escolar-sinopse-sinopse>. Acesso em: 20 nov. 2012.

BRASIL. Conselho Nacional de Educação (CNE). Conselho Nacional de Educação (CNE). Câmara de Educação Básica (CEB). Resolução CNE n ${ }^{\circ}$ 02, de 28 de maio de 2008. Estabelece as diretrizes complementares, normas e princípios para o desenvolvimento de políticas públicas de atendimento da educação básica do campo. Diário Oficial da União, 29 abr. 2008. Seção 1, p. 41-42. Disponível em: <http://portal.mec.gov.br/ cne/arquivos/pdf/2008/rceb002_08.pdf>. Acesso em: 25 jun. 2012.

CAVALCANTE, Ludmila Oliveira Holanda. Das políticas ao cotidiano: entraves e possibilidades para a educação do campo alcançar as escolas 
no rural. Ensaio: aval.pol.públ.Educ, Rio de Janeiro, v.18, n. 68, p. 549564, 2010. Disponível em: <http://www.scielo.br/scielo.php?script=sci_ arttext\&pid $=$ S0104-40362010000300008\&lng =pt\&nrm=iso $>$.

HAGE, Salomão Mufarrej (Org.). Educação do campo na Amazônia: retratos de realidade das escolas multisseriadas do Pará. Belém: Gutemberg, 2005.

HAGE, Salomão Mufarrej; ANTUNES-ROCHA, Maria Isabel (Org.). Escola de direito: reinventando a escola multisseriada. Belo Horizonte: Autêntica, 2010.

LIMA, Elvira C. Souza. Ciclos de formação: uma reorganização do tempo escolar. São Paulo: Ed. Sobradinho 107, 2002.

LITTLE, Angela. Learning and teaching in multigrade settings: [paper for Unesco EFA Global Monitoring Report 2005]. 2004. Disponível em: <http://siteresources.worldbank. org/INTINDIA/43714321194542398355/21543231/ LearningandTeachinginMulti-Gradeclassrooms.pdf $>$. Acesso em: 25 jun. 2012.

LITTLE, Angela. Multigrade teaching: a review of practice and research. London: Overseas Development Administration, 1995.

MOLINA, M. C.; JESUS, Sonia Meire S. A. de (Org.). Por uma educação do campo. Brasília, DF: NEAD, 2004. (Por uma Educação do Campo, n. 5).

PARENTE, Cláudia da Mota Darós. A construção dos tempos e espaços escolares: possibilidades e alternativas plurais. Tese (Doutorado em Educação) - Universidade Estadual de Campinas, Campinas, 2006. Disponível em: <http://www.bibliotecadigital.unicamp.br/document/?co de $=$ vtls000390970\&opt=1>. Acesso em: 25 jun. 2012.

PARENTE, Cláudia da Mota Darós. A construção dos tempos escolares. Educação em Revista, Belo Horizonte, v. 26, n. 2, p. 135-156, ago. 2010. Disponível em: <http://www.scielo.br/scielo.php?script=sci_arttext\&pid =S0102-46982010000200007>. Acesso em: 30 jul. 2013.

PRIDMORE, P. Adapting the primary school curriculum for multigrade classes: a 5-step plan and an agenda for action. Journal of Curriculum Studies, v. 39, n. 1, p. 559-576, 2007. Disponível em: <http://eprints.ioe. ac.uk/3749/1/Pridmore2007Adapting559.pdf > . Acesso em: 25 jun. 2012.

SIGSWORTH, Alan; SOLSTAD, Karl Jan. Small rural schools: a small inquiry. Cornwall: Interskola, 2005. Disponível em: <http://www. hinesna.no/system/files/skriftserie/64.pdf>. Acesso em: 25 jun. 2012. 
Cláudia da Mota Darós Parente, doutora em Educação pela Universidade Estadual de Campinas (Unicamp), é professora da Faculdade de Filosofia e Ciências da Universidade Estadual Paulista Júlio de Mesquita Filho (Unesp), Departamento de Administração e Supervisão Escolar (Dase), campus Marília, São Paulo, Brasil.

claudiadaros@hotmail.com

Recebido em $1^{\circ}$ de agosto de 2013.

Revisado em 16 de janeiro de 2014.

Aprovado em 4 de setembro de 2014. 